\title{
Assessment of learning style preferences of medical undergraduate students: A cross-sectional study
}

Ranganath T. S., Josephine Priya K.

Department of Community Medicine, Bangalore Medical College and Research Institute,

Bangalore, Karnataka, India

Address for the Correspondence:

Dr. K. Josephine Priya, 519/F/52, $14^{\text {th }}$ Main, Gokul, Phase 1, Stage 1, Mathikere, Bengaluru - 560 054, Karnataka, India. E-mail: josephinek87@gmail.com

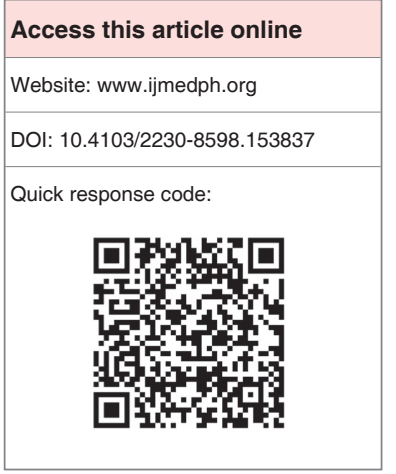

Context: As doctors who are also teachers we must be aware of the various learning styles used by our students. Each style is unique in how a student takes in knowledge. Thus to maximize output, we need to facilitate their learning process as teachers. Aims: This study was undertaken to assess the predominant learning style of $2^{\text {nd }}$ year medical students and to compare the learning modality used with the academic performance. Settings and Design: Cross-sectional study undertaken in a Government Medical college of Bangalore, Karnataka, India. Materials and Methods: A total of 210 second year medical undergraduates in a Government Medical College, Bangalore were asked to fill a pre tested and pre validated visual, auditory, read/ write, kinesthetic questionnaire, version 7.3 developed by Neil Fleming. The students were then scored to assess the predominant learning modality used. Statistical Analysis Used: Data were analyzed using SPSS version 20. Descriptive statistics, Chi-square test, Fisher's test and unpaired (two sample) $t$-test were used to study the variables. Results: Majority of the students were multimodal (61\%). Kinesthetic was the predominant modality used, both among unimodal $(56.8 \%)$ and multimodal $(31.8 \%)$ learners. There was no significant difference in the learning modalities of male and female students. There was also no difference in academic performance of uni- and multi-modal learners. Conclusions: Current teaching styles do not support the student fraternity that is predominantly multimodal. Various workshops must be conducted to train teachers to adapt their teaching styles. Multiple methods must be used simultaneously deliver knowledge and information to the students to improve their acceptance.

Key words: Learning styles, medical students, multimodal, unimodal, visual auditory $\mathrm{read} /$ write kinesthetic

\section{INTRODUCTION}

Medical education places a great strain on young intellectual minds. Faced with an overload of knowledge, they are expected to assimilate much more in lesser time than they are accustomed to. The $1^{\text {st }}$ year of the $5 \frac{1}{2}$ years under graduation course is spent trying to come to terms with the changes in lifestyle, strain, new subjects, a new approach to the field, etc. In the $2^{\text {nd }}$ year of medical education, most students have developed a pattern of learning that they think is most beneficial to them. It is important to find out whether students tend to predominantly favor one modality of learning or a combination of them. It is also important to know this in order to tailor a teacher's teaching methodology to suit his/her students.

Learning styles are different and unique ways used by individuals as they prepare to learn and recall information. ${ }^{[1]}$ Educational researchers postulate that each individual has a unique learning style. ${ }^{[2]}$ The visual auditory read/write kinesthetic (VARK) inventory lists the predominant learning styles to be visual (V), auditory (A), read/write $(\mathrm{R})$ or kinesthetic $(\mathrm{K})$. Visual learners learn by looking at and making pictures, animations, graphs, tables, charts, etc. Aural learners learn by listening to and participating in speeches, discussions, and question and answer sessions. Those favoring the read-write style learn by reading and writing text associated with the books, class notes, etc., and the kinesthetic learners learn by engaging in physical experiences, manipulating objects, etc. ${ }^{[3]}$ 
Some studies have shown that school performance of students correlates poorly with their university performance. ${ }^{[4]}$ Not many studies look at the relation between the learning modality used and the academic success of these students. While various studies have been undertaken to assess the learning style preference of students, only very few have looked at the same among medical students. Even then, most of the studies are done among medical students from western countries and the students are predominantly from the pre medical level.

We felt a need to study the learning styles employed by our undergraduate students to help faculty understand their needs and modify teaching patterns. Gaining insight into the learning modalities preferred and used by our students enables teachers to facilitate better learning. This study was undertaken to assess the predominant learning styles of $2^{\text {nd }}$ year medical students and to compare the learning modality used with academic performance.

\section{MATERIALS AND METHODS}

This is a cross-sectional study carried out among all $2^{\text {nd }}$ year medical undergraduates at a government medical college, Bangalore. The study period was from January 2014 to June 2014. The study and its purpose were explained to the students. They were briefed about the meaning of VARK learning modalities to help them identify which modality they thought they used. Of 223 students, 210 consented to participate in the study. A VARK questionnaire version 7.3 developed by Neil Fleming was used. ${ }^{[5]}$ This questionnaire was administered to all students in hard copy. The questionnaire contains 16 questions with four options to each. A student may mark one or more options to each question. The answers were then scored as V, A, R or K based on the key given in the guide. Based on the instructions given for the VARK inventory, scores were calculated to determine the predominant learning modality used by each individual. Socio demographic data was also collected separately. B G Prasad Classification was used to classify the students into the various socioeconomic classes as they were found to be a mixed group of both urban and rural backgrounds. Class I was considered upper class, II and III were considered middle class while class IV and V were classified as lower class to facilitate analysis.

Academic performance of the student was assessed on the basis of his/her $1^{\text {st }}$ year MBBS final average score. Students were asked to state what they thought was their preferred learning modality and also, according to them, which modality was supported by the teaching methods used in their college.

The data collected was entered into Microsoft office excel worksheets (Microsoft Corporation, WA, USA). It was analyzed using SPSS version 20. Sociodemographic data were summarized using descriptive statistics. Chi-square test was used to test for impact of socioeconomic status and learning styles and also gender differences in learning. Unpaired (two sample) $t$-test was used to study the relationship between the learning modality used and the academic performance in college.

\section{RESULTS}

The sociodemographic details of the 210 students who consented to participate in the study are given in Table 1.

Students were classified as unimodal or multimodal learners depending on whether they predominantly used a single learning modality (V, A, R or K) or a combination of these (VA, RK, VAR, VARK, etc.). Those who used a combination of two learning modalities (VA, AR, RK, etc.) were classified as bimodal learners. Those using three (VAR, RAK, KVR, etc.) are trimodal learners and those using all four (VARK) are quadmodal learners. Accordingly, as shown in Figure 1, students were predominantly found to be multimodal in their learning style preference $(n=128,61 \%)$. Among these, quadmodal learners form the majority $(n=61,29 \%)$.

Figure 2 shows among the unimodal learners, the kinesthetic method of learning was the most predominant style used ( $n=119,56.8 \%)$. This was followed by aural $(n=52,24.8 \%)$, read/write $(6.2 \%)$ and visual $(4.9 \%)$. Even among those who were multimodal in their learning styles, majority $(31.8 \%)$ strongly favored the kinesthetic method over the others even though they used $>1$ learning style.

The unpaired (two sample) $t$-test was done to compare the difference in academic performance of unimodal and multimodal learners in

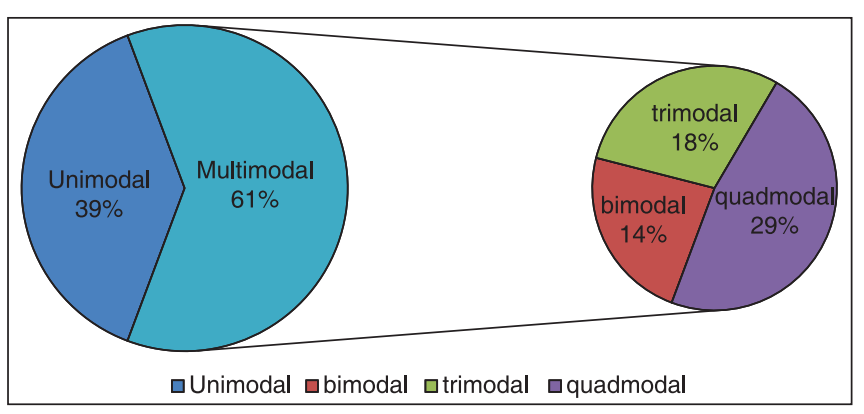

Figure 1: Learning modality of the medical students

\begin{tabular}{lcc} 
Table 1: Sociodemographic details & \\
\hline Characteristics & $\boldsymbol{n = 2 1 0}$ & Percentage \\
\hline Males & 144 & 68.6 \\
Females & 66 & 31.4 \\
Socioeconomic status (BG & & \\
Prasad scale) & & \\
I & 48 & 22.9 \\
II & 121 & 57.6 \\
III & 23 & 11 \\
IV & 2 & 1 \\
V & 0 & 0 \\
Religion & & \\
Christian & 10 & 4.8 \\
Hindu & 179 & 85.2 \\
Jain & 2 & 1.0 \\
Muslim & 9 & 4.3 \\
Sikh & 1 & 0.5 \\
Mean age of students & 18.75 years $( \pm 2.32)$ \\
\hline
\end{tabular}


medical college. It was seen that there was no significant difference in their performance [Table 2].

There was no significant difference in the learning style modality adopted by male and female students as assessed by the Chi-square test [Table 3]. Also on using the Fisher's exact test, there was no significant difference in the learning style modalities used by students belonging to different socioeconomic classes [Table 3].

Most students believed that they predominantly used the visual modality $(25.7 \%)$ but when assessed majority were found to favor the kinesthetic modality. Only $12.85 \%(n=27)$ students were able to correctly state their learning modality.

\section{DISCUSSION}

Learning modalities are the sensory channels or pathways through which individuals give, receive, and store information. Visual,

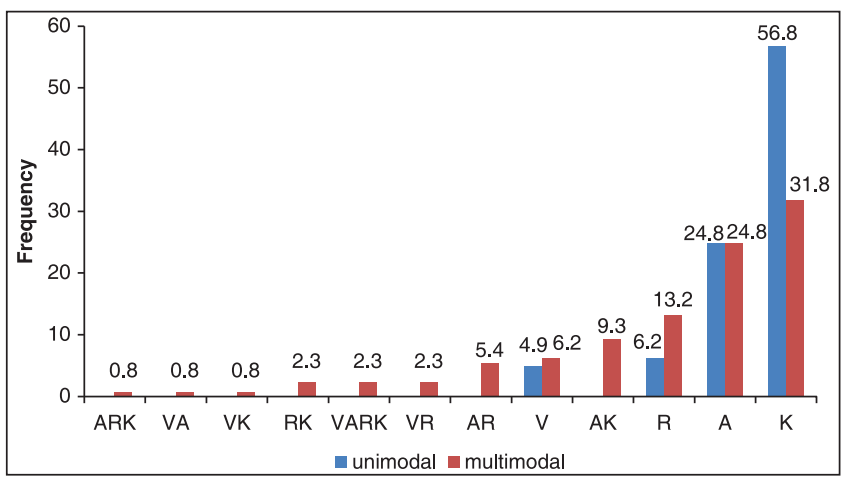

Figure 2: Predominant learning style preferences of the medical students

\begin{tabular}{|c|c|c|c|c|}
\hline Learning modality & $\begin{array}{c}\text { Average } 1^{\text {st }} \text { MBBS } \\
\text { score }(\%)\end{array}$ & SD & $n$ & $P$ \\
\hline Unimodal & 68.19 & 12.46 & 81 & 0.22 \\
\hline Multimodal & 65.43 & 17.67 & 129 & \\
\hline Total & & & 210 & \\
\hline
\end{tabular}

$\mathrm{SD}=$ Standard deviation

\begin{tabular}{|c|c|c|c|c|}
\hline \multirow[t]{2}{*}{ Characteristics } & \multicolumn{2}{|c|}{ Learning modality } & \multirow[t]{2}{*}{ Total } & \multirow[t]{2}{*}{$P$} \\
\hline & Unimodal & Multimodal & & \\
\hline \multicolumn{5}{|l|}{ Gender } \\
\hline Male & 56 & 88 & 144 & 0.89 \\
\hline Female & 25 & 41 & 66 & \\
\hline Total & 129 & 81 & 210 & \\
\hline \multicolumn{5}{|c|}{ Socioeconomic status } \\
\hline Upper & 18 & 30 & 48 & 0.86 \\
\hline Middle & 53 & 91 & 144 & 0.43 \\
\hline Lower & 2 & 0 & 2 & 0.14 \\
\hline Total & 121 & 73 & 194 & \\
\hline
\end{tabular}

auditory, tactile, kinesthetic, smell, taste, etc., are the various modalities. In a classroom, the visual, auditory, read/write and kinesthetic were found to be predominant. ${ }^{[6]}$

Our study showed that $61 \%$ of our students are multimodal and this is comparable to the findings of numerous other studies. It was highly similar to a study done by Kharb et al. wherein $61 \%$ of the students were multimodal. ${ }^{[7]}$ A study by Lonie $e t$ al. among graduate medical anatomy students, University of Wisconsin School of Medicine and Public Health, showed that $71 \%$ are multimodal learners and $29 \%$ are unimodal. ${ }^{[8]}$ In medical colleges powerpoint presentations are currently the predominant mode of instruction. Students go back and read their text books to further understand what has been taught. Thus, our teaching methods are supportive of visual and auditory learners. From this study, it is evident that we are teaching a student population that is predominantly kinesthetic. It has been suggested that to improve and maximize learning process for these students, methods such as visits to laboratories, field trips and tours, giving real-life examples, hands-on approaches (computing), trial and error, exhibits, samples, photographs, etc., can be used. ${ }^{[9]}$

This study also showed that there was no significant difference in academic performance of unimodal and multimodal learners. Furthermore, there was no difference in the modalities adopted by males and females for learning. In a study by Baykan and Naçar among $1^{\text {st }}$ year medical students of Erciyes University in Kayseri, Turkey the learning styles did not differ between male and female students $(P>0.05)$, and no statistically significant difference was determined between first-semester grade point averages and learning styles $(P>0.05) \cdot{ }^{[10]}$ In a study by Ramirez, Chile, done on $2^{\text {nd }}$ year undergraduate medicine and sport science students, MCQ test grades between the 97 unimodal (66.5 \pm 12.2 , mean \pm standard deviation $[S D])$ and 153 multimodal (65.4 \pm 12.3 , mean $\pm \mathrm{SD})$ students were compared, no significant differences were detected ( $P=$ not significant by Mann-Whitney U-test). ${ }^{[1]}$ However, one study by Wehrwein et al., among undergraduate physiology students in Michigan found that there were significant differences in the learning style preferences of its male and female students. ${ }^{[12]}$

\section{CONCLUSION}

As professionals in the field of Community Medicine, we play a significant role not only in the field but also in college. Unmatched learning styles and teaching - learning methodologies may adversely affect the learning on the part of the students. ${ }^{[13]}$ We must tailor our teaching styles to suits the needs of our students. An effective teaching program must be incorporated in all medical colleges to ensure that the learning experience is an enjoyable and enriching one for all medical students.

The limitation of this study is that it does not take into consideration whether there is better performance among students who are predominantly visual and/or aural in their learning in a teaching 
atmosphere that is promotive of their learning style. This could be taken up as further research in this field.

Thus, we can conclude that we need to shift from classroom teaching and incorporate various different styles to teach our multimodal learners.

\section{REFERENCES}

1. Samarakoon L, Fernando T, Rodrigo C. Learning styles and approaches to learning among medical undergraduates and postgraduates. BMC Med Educ 2013;13:42.

2. Murphy RJ, Gray SA, Straja SR, Bogert MC. Student learning preferences and teaching implications. J Dent Educ 2004;68:859-66.

3. Vark-learn.com. The VARK Modalities | VARK; 2014. Available from: http://www.vark-learn.com/english/page.asp? $\mathrm{p}=$ categories. [Last cited on 2014 Sep 21].

4. Peers I, Johnston M. Influence of learning context on the relationship between A-level attainment and final degree performance: A metaanalytic review. Br J Educ Psychol 1994;64:1-18.

5. Vark-learn.com. The VARK Questionnaire I VARK; 2014. Available from: http://www.vark-learn.com/the-vark-questionnaire/?p=questionnaire. [Last cited on 2014 Sep 21].

6. Web.cortland.edu. Modalities; 2014. Available from: http:// www.web.cortland.edu/andersmd/learning/modalities.htm. [Last cited on 2014 Sep 25].
7. Kharb P, Samanta PP, Jindal M, Singh V. The learning styles and the preferred teaching-learning strategies of first year medical students. J Clin Diagn Res 2013;7:1089-92.

8. Lonie R, Thapar N, Munoz A, Krabbenhoft K. Student Learning Styles and their Impact on Performance in the Study of Human Anatomy; 2010. Available from: https://www.radiology.wisc.edu/fileShelf/posters/2010_ AACA Salkowski.pdf. [Last cited on 2014 Sep 24].

9. Vark-learn.com. Kinesthetic Strategies | VARK; 2014. Available from: http://www.vark-learn.com/english/page.asp?p=kinesthetic\#. [Last cited on 2014 Sep 25].

10. Baykan Z, Naçar M. Learning styles of first-year medical students attending Erciyes University in Kayseri, Turkey. Adv Physiol Educ 2007;31:158-60.

11. Ramirez BU. The sensory modality used for learning affects grades. Adv Physiol Educ 2011;35:270-4.

12. Wehrwein EA, Lujan HL, DiCarlo SE. Gender differences in learning style preferences among undergraduate physiology students. Adv Physiol Educ 2007;31:153-7.

13. Felder R, Brent R. Understanding student differences. J Eng Educ 2005;94:57-72.

How to cite this article: Ranganath TS, Priya KJ. Assessment of learning style preferences of medical undergraduate students:

A cross-sectional study. Int J Med Public Health 2015;5:196-9.

Source of Support: Nil, Conflict of Interest: None declared. 